\title{
Loc Depecker, Entre signe et concept - Eléments de terminologie générale
}

\section{Rachele Raus}

\section{(2) OpenEdition}

10 Journals

\section{Édition électronique}

URL : https://journals.openedition.org/studifrancesi/39982

DOI : 10.4000/studifrancesi.39982

ISSN : 2421-5856

Éditeur

Rosenberg \& Sellier

\section{Édition imprimée}

Date de publication : 1 décembre 2004

Pagination : 429-430

ISSN : 0039-2944

\section{Référence électronique}

Rachele Raus, «Loc Depecker, Entre signe et concept - Eléments de terminologie générale », Studi

Francesi [En ligne], 143 (XLVIII | II) | 2004, mis en ligne le 30 novembre 2015, consulté le 19 mai 2021.

URL : http://journals.openedition.org/studifrancesi/39982 ; DOI : https://doi.org/10.4000/

studifrancesi.39982

Ce document a été généré automatiquement le 19 mai 2021.

\section{(c)}

Studi Francesi è distribuita con Licenza Creative Commons Attribuzione - Non commerciale - Non opere derivate 4.0 Internazionale. 


\title{
Loc Depecker, Entre signe et concept - Eléments de terminologie générale
}

\author{
Rachele Raus
}

\section{RÉFÉRENCE}

LOC DEPECKER, Entre signe et concept - Eléments de terminologie générale, Paris, Presses de la Sorbonne Nouvelle, 2002, pp. 199.

1 Ce livre se veut une réflexion sur la méthode utilisée actuellement en terminologie, l'A. participant aux travaux des commissions officielles dans l'espace francophone et à l'ISO. Tout travail de standardisation opère une démarche onomasiologique (de la définition de l'objet au terme). Cela permet à l'A. de renverser la méthode utilisée en linguistique (du signe à la définition de l'objet) et de préciser la différence entre signifié en linguistique et concept en terminologie, ce dernier étant considéré dans le sens de la tradition logique et non pas cognitive, c'est-à-dire comme "unité structurée de pensée" (p. 43). Si à un signe peuvent correspondre plusieurs signifiés (polysémie), la démarche terminologique vise la monosémie, définissant l'objet de façon précise et absolue et donnant ensuite le terme correspondant, qui ne peut donc être qu'un. Cette démarche opère une sorte de généralisation du concept qui sera ensuite adaptée aux structures particulières des différentes langues: au fond, même le terme résulte être un "signe vivant" (p. 56). La terminologie est donc redéfinie comme discipline qui "traite traditionnellement du terme, c'est-à-dire, ...d'un ensemble constitué d'un concept et d'une désignation" (p. 64). La réflexion terminologique permet alors d'observer de près la relation objet-signe-concept et de fournir des instruments et des observations utiles à la linguistique. L'A. espère donc relier ces deux disciplines. L'A. fournit, en outre, les critères utilisés pour dresser des systèmes terminologiques à partir des liens entre concepts, soulignant le fait que le but de l'ISO est bien de créer un "système international de notions" (p. 95), là où "notion" est à considérer justement comme 
"concept". La deuxième partie du texte est consacrée à une sorte de bibliographie raisonnée sur les notions et les observations présentées dans la première partie. 